\title{
Host-pathogen interaction for screening potential of Metarhizium anisopliae isolates against the date-palm dust mite, Oligonychus afrasiaticus (McGregor) (Acari: Tetranychidae)
}

\author{
Abid Hussain 1*, Muhammad Rizwan-ul-haq ${ }^{1}$, Ahmed Mohammed AlJabr ${ }^{1 *}$ [D and Hassan Al-Ayedh 2,3,4*
}

\begin{abstract}
Impact of virulence-determining traits of the fungus, Metarhizium anisopliae (Sensu lato), isolates 2049, 8762, and 7234, on mortality rate of the date-palm dust mite, Oligonychus afrasiaticus (McGregor) (Acari: Tetranychidae), and host antioxidant defense-related enzymes were evaluated. Laboratory bioassays showed significant differences in the mortality rates of the mite species against fungal infection. Isolate $2049\left(L T_{50}=6.43\right.$ days; $L C_{50}=2.37 \times 10^{6}$ conidia/ml) was the most virulent one, revealing (160.64\%) higher activity of the cuticle-degrading Protease ( $\operatorname{Pr} 1)$ than least virulent isolate $7234\left(\mathrm{LT}_{50}=18.44\right.$ days; $\mathrm{LC}_{50}=2.18 \times 10^{8}$ conidia/ml). The invading conidial suspensions of the most virulent isolate 2049, established in the present study, successfully evaded the antioxidant-defense mechanism, and resulted in low relative enzymatic activities of the catalases, superoxide dismutases, and glutathione S-transferases, at the lateral stages of infection. The obtained results concluded that M. anisopliae isolate 2049 could be an attractive candidate for the mycopathogen development of controlling date-palm dust mite, O. afrasiaticus.
\end{abstract}

Keywords: Entomopathogens, Metarhizium anisopliae, Oligonychus afrasiaticus, Virulence, Antioxidants, Mortality

\section{Background}

Date-palm, Phoenix dactylifera L, native to the Arabian Peninsula regions, is one of the oldest domesticated fruit trees with socio-economic importance. This cash crop can be successfully grown in the desert not only because of minimum water requirements, but also being highly tolerant to salinity and harsh weather conditions (Diallo 2005). There is a tremendous decline in the annual yield $(\mathrm{Hg} / \mathrm{Ha})$ of dates in the Kingdom of Saudi Arabia (KSA) compared to the world's yield of dates. Many injurious

\footnotetext{
* Correspondence: abhussain@kfu.edu.sa; aljabr@kfu.edu.sa; alayedh@kacst.edu.sa

'Laboratory of Bio-Control and Molecular Biology, Department of Arid Land Agriculture, College of Agricultural and Food Sciences, King Faisal University, Hofuf, 31982 Al-Ahsa, Kingdom of Saudi Arabia

${ }^{2}$ National Agriculture Technology Center, Life science and Environment Research Institute, King Abdulaziz City for Science and Technology, P.O. Box 6086, Riyadh 11442, Kingdom of Saudi Arabia

Full list of author information is available at the end of the article
}

pests are the main factor that threatens dates production. Among these pests, the date-palm dust mite, Oligonychus afrasiaticus (McGregor) (Acari: Tetranychidae) is one of the major pests that attack datepalm fruits in the KSA.

The management of $O$. afrasiaticus primarily relies on frequent use of synthetic acaricides and other chemical compounds. Dependence on acaricides is ecologically questionable due to public health concerns, pollution, and food safety issues (El-Saeid and Al-Dosari 2010). Furthermore, pesticide usage is discouraged due to the harmful side effects of killing non-target and beneficial species (Amalin et al. 2000). In addition, acaricides are not considered for the long-term management of $O$. afrasiaticus because of problems of pest resurgence, environmental pollution, costliness, applicator safety, and the persistence of residues in the fruits. These concerns raised the 
dire need to research eco-friendly alternate measures for the management of $O$. afrasiaticus. Consequently, use of biological control agents such as entomopathogenic fungi (EPF) has become an acceptable technique.

Naturally occurring EPF is considered an important alternative in reversing agriculture's hazardous dependence on acaricides/pesticides. Most EPF belongs to Entomophthorales and Hypocreales. Currently, approximately 51 genera with 9000 isolates of EPF species have been reported to infect numerous pest species (Hussain et al. 2018 and Ali et al. 2018). Many studies have been carried out to explore the bio-control potential of EPF against different species of mites other than $O$. afrasiaticus. The only study conducted against the date-palm dust mite was mainly focused on the synergistic response of fungal conidia with Phytol to enhance their response (AlJabr et al. 2018).

The present study aimed to evaluate the virulence of $M$. anisopliae isolates against the date-palm dust mite, $O$. afrasiaticus under laboratory conditions and to gain insights into the antioxidant defense mechanism against fungal infections.

\section{Materials and methods}

\section{Mite collection and maintenance}

Infested date-palm fruits with $O$. afrasiaticus were collected from the National Center for Palms and Dates, Al-Ahsa, KSA and King Faisal University Research areas, KSA in 2017. The mites were incubated under laboratory conditions $\left(25 \pm 1{ }^{\circ} \mathrm{C}, 62.5 \pm 12.5 \%\right.$ R.H., and a 16 : $8 \mathrm{~h}$ (L:D) photoperiod).

\section{Biological control agent}

Entomopathogenic fungus, Metarhizium anisopliae, isolates $(2049,8762$, and 7234$)$ were used to evaluate their potential against $O$. afrasiaticus. EPF isolates were grown on potato dextrose agar (Oxoid, Hampshire, UK) in Petri plates $(115 \times 20 \mathrm{~mm})$. After inoculation, cultures were kept at $25 \pm 0.5{ }^{\circ} \mathrm{C}, 70 \% \pm 5 \% \mathrm{RH}$ in complete darkness.

\section{Evaluation of virulence factors Conidial viability}

A 24-day-old culture of each tested isolate was harvested, using a sterile scalpel to prepare conidial suspension, using $0.05 \%$ Tween 80 (Sigma-Aldrich Cat \# P4780). Conidial suspension with a concentration of $1 \times 10^{7}$ conidia $/ \mathrm{ml}$ was prepared under a compound microscope $(\times 400)$, using a Neubauer hemocytometer (Wertheim, Germany). The conidial viability of each $M$. anisopliae isolate was determined by inoculating 5 PDA-Petri dishes $(5.5 \mathrm{~cm})$ with $50 \mu \mathrm{l}$ conidial suspension $\left(1 \times 10^{7}\right.$ spores $\left./ \mathrm{ml}\right)$.
Viability data were calculated after $18 \mathrm{~h}$ post-inoculation as described by Hussain et al. (2010). Each experimental unit's percent viability was calculated by viewing 100 conidia at $\times 400$ magnification under compound microscope.

\section{Cuticle degrading protease activity}

The protease ( $\operatorname{Pr} 1)$ activity of the conidial suspensions of all tested isolates was assayed by recording the release of nitroanilide (NA) at $405 \mathrm{~nm}$, using succinylAla-Ala-Pro-Phe- $p$-nitroanilide substrate as described by Hussain et al. (2015).

\section{Laboratory pathogenicity bioassays}

The pathogenicity of each isolate of $M$. anisopliae was calculated on the basis of $\mathrm{LT}_{50}$ (lethal time to $50 \%$ mortality) and $\mathrm{LC}_{50}$ (lethal concentration to $50 \%$ mortality). The $\mathrm{LT}_{50}$ values for all tested isolates were calculated by infecting the date-palm dust mite with a single concentration. In brief, conidial suspension with a single concentration $\left(1 \times 10^{7}\right.$ conidia/ml $)$, separately prepared for each isolate, was used to dip pesticide-free date-palm leaf disks (length $7.5 \times$ width $4 \mathrm{~cm}$ ). After air-drying, 25 mite individuals (deutonymphs), with the aid of a camel-hair brush, were transferred on the leaves, surrounded with a wet cotton. Control treatment of the date-palm leaf disks was likewise prepared using $0.05 \%$ Tween 80 . Five replicates, using 5 different populations, were prepared and incubated at $25 \pm 1{ }^{\circ} \mathrm{C}, 62.5 \pm 12.5 \% \mathrm{RH}$, and a 16:8 h (L:D) photoperiod. In addition, the study was repeated in the next season. Conidial response in terms of host mortality was recorded daily to calculate $\mathrm{LT}_{50}$ values, using Probit analysis.

In the case of $\mathrm{LC}_{50}$ determination, 5 concentrations $\left(1 \times 10^{5}, 1 \times 10^{6}, 1 \times 10^{7}, 1 \times 10^{8}\right.$, and $1 \times 10^{9}$ conidia $\left./ \mathrm{ml}\right)$ for each isolate were prepared in $0.05 \%$ Tween 80 . Pesticide-free date-palm leaf disks (length $7.5 \times$ width $4 \mathrm{~cm}$ ) were separately dipped into the 5 different concentrations. Twenty-five date-palm dust mites (deutonymphs) were carefully transferred on dampened cotton, using a camel-hair brush. In the case of the control, leaf disks were treated by a $0.05 \%$ Tween 80 solution. Five replicates were prepared using five different populations. Each experimental unit was incubated under controlled conditions, disclosed in the above section. Concentration-mortality response was recorded every $24 \mathrm{~h}$ to calculate the $\mathrm{LC}_{50}$, using Probit analysis. In both tests, dead mites were surface-sterilized and shifted into Petri dishes lined with dampened sterile filter paper. Mycosis of the inoculating fungal isolate was confirmed by microscopic examination. 
Antioxidant defense mechanism of date palm dust mites

A single concentration $\left(1 \times 10^{7}\right.$ conidia/ml $)$ of each tested isolate was used to infect the mites. Approximately, 1000 deutonymphs were allowed to feed for 9 days on conidial suspension treated with date-palm leaf disks. Overall, 3 mite samples (3, 6, and 9 days) with a 3-day difference for enzyme analysis were taken for homogenization under icecold potassium phosphate buffer in a glass homogenizer. After centrifugation, each supernatant was used to quantify protein, using Bradford (1976) methodology.

Catalase (CAT) activity was calculated, following the Aebi (1984) methodology. In brief, $25 \mu$ l of the sample was mixed with $665 \mu \mathrm{l}$ of $50 \mathrm{mM}$ PBS buffer and $10 \mu \mathrm{l}$ of $\mathrm{H}_{2} \mathrm{O}_{2}$ to determine their absorbance in the spectrophotometer at $240 \mathrm{~nm}$. Five replicates were likewise prepared.

Superoxide dismutase (SOD) activity of each sample was calculated with the Beauchamp and Fridovich (1971) methodology, mainly based on the generation of superoxide anions in the presence of light in response to reduce flavins. Five replicates were separately likewise prepared.

Glutathione S-transferase (GST) activities were calculated following the Habig et al. (1974) protocol, using chloro-dinitro-benzene (CDNB) and dichloronitrobenzene (DCNB). The homogenated sample was added into the microplate reader for $5 \mathrm{~min}$ for equilibration in the presence of CDNB and reduced glutathione. Absorbance was recorded in the spectrophotometer at $340 \mathrm{~nm}$. Five replicates were prepared.

\section{Statistical analysis}

The data on conidial viability (\%) and Pr1 activities ( $\mu \mathrm{m} \mathrm{NA}$ released $/ \mathrm{ml} / \mathrm{min}$ ) were analyzed by one-way ANOVA. The mortality data of date-palm dust mites were angularly transformed. Abbott's formula was used to correct the mortality rates of the mites (Abbott 1925). The data of the mortality rates and of the enzymatic activities of CAT, SOD, and GST relative to control treatment were analyzed by repeated measures ANOVA. Differences among the means were compared with Fisher's LSD test (Statistix 2003).

\section{Results and discussion} Pathogen virulence

The present study revealed that all isolates exhibited more than $96 \%$ conidial viability $(F=0.36$; $\mathrm{df}=2,12$; $P=0.708)$, even from the least virulent studied isolate 7234 . These findings are in agreement with previous studies indicating that low virulence among highly viable isolates of fungi reflects that virulence is regulated by multiple sets of traits (Hussain et al. 2015 and Hussain et al. 2016). In the present study, significant differences $(F=101$; df $=2,12 ; P<0.0001)$ in $\operatorname{Pr} 1$ activity in all of the studied
EPF isolates were also recorded. Among all isolates, 2049 showed the highest Pr1 activity. The highest Pr1 activity from the most pathogenic isolate was consistent with St. Leger et al. (1987b), who found that Pr1 is an important pathogenicity determinant by providing nutrition to the pathogen and assistance in host cuticle penetration. The highest levels of Pr1, as observed previously by biochemical, immunological, and histochemical assays (St. Leger et al. 1987a), and confirmed here from the most pathogenic isolate (2049), revealed the significance of this enzyme in host pathogenesis. A previous study also revealed that $\operatorname{Pr} 1$ inhibition led to a delay in the disease symptoms of the target host, Manduca sexta (St. Leger et al. 1988). Hussain (2018) studied the reprogramming of virulence and strengthened the present study's findings by revealing that the invading pathogen, especially fungal isolate virulence, was directly proportional to its expressions of protease enzymes and their genes. Similar enzymatic activities and their expressions were also depicted in the present study, enabling us to suggest that, among virulence factors, protease enzymes can play a pivotal role in the virulence of the tested isolates.

\section{Pathogenicity assessment of Metarhizium anisopliae isolates} Susceptibility of the date-palm dust mite to infection with different isolates of $M$. anisopliae at a single-tested concentration $\left(1 \times 10^{7}\right.$ conidia/ml $)$ varied significantly among isolates $(F=3576.72 ; \mathrm{df}=2,40 ; P<0.0001)$, time intervals $(F=173.65$; df $=4,40 ; P<0.0001)$, and their interactions $(F=51.75 ; \mathrm{df}=8,40 ; P<0.0001)$, as shown in Fig. 1. The conidial suspension of $M$. anisopliae 2049 found to be a highly virulent isolate due to its lowest $\mathrm{LT}_{50}$ value (6.43 days; Table 1 ). Furthermore, infection of the same isolate 2049 in O. afrasiaticus also showed the highest mortality rate $(85.20 \%)$ during the

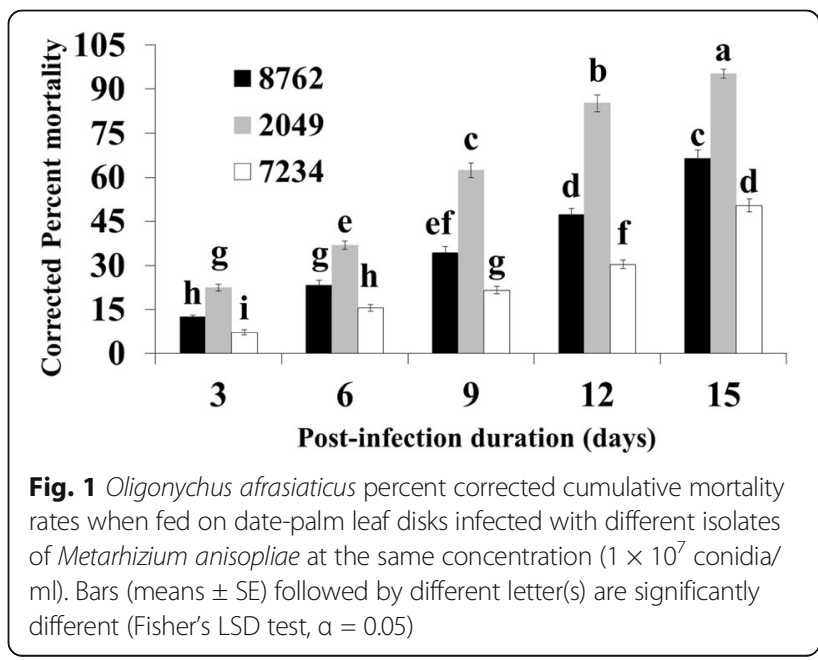


Table 1 Susceptibility of Oligonychus afrasiaticus to various isolates of Metarhizium anisopliae under laboratory conditions

\begin{tabular}{|c|c|c|c|c|}
\hline Fungal isolates & $\mathrm{LT}_{50}(95 \% \mathrm{Cl})(\text { days })^{*}$ & $\begin{array}{l}\mathrm{LC}_{50}(95 \% \mathrm{Cl}) \\
\text { (conidia/ml)† }\end{array}$ & $\begin{array}{l}\text { Conidial viability } \\
(\%)\end{array}$ & $\begin{array}{l}\text { Pr1 activity } \\
(\mu \mathrm{mol} \mathrm{NA} / \mathrm{ml} / \mathrm{min})\end{array}$ \\
\hline 2049 & $\begin{array}{l}6.43 \\
(3.89-10.63)\end{array}$ & $\begin{array}{l}2.37 \times 10^{6} \\
\left(1.34 \times 10^{6}-4.20 \times 10^{6}\right)\end{array}$ & $96.60 \pm 0.68^{\mathrm{a}}$ & $2.45 \pm 0.05^{a}$ \\
\hline 8762 & $\begin{array}{l}11.86 \\
(10.26-13.70)\end{array}$ & $\begin{array}{l}7.77 \times 10^{7} \\
\left(3.51 \times 10^{7}-1.72 \times 10^{8}\right)\end{array}$ & $97.20 \pm 1.02^{a}$ & $1.47 \pm 0.09^{b}$ \\
\hline 7234 & $\begin{array}{l}18.44 \\
(14.40-23.62)\end{array}$ & $\begin{array}{l}2.18 \times 10^{8} \\
\left(9.45 \times 10^{7}-5.02 \times 10^{8}\right)\end{array}$ & $96.20 \pm 0.80^{\mathrm{a}}$ & $0.94 \pm 0.09^{c}$ \\
\hline
\end{tabular}

* $\mathrm{LT}_{50}$ lethal time to kill $50 \%$ population of date-palm dust mites

$+\mathrm{LC} \mathrm{C}_{50}$ lethal concentration to kill $50 \%$ population of date-palm dust mites

Means \pm SE values with different letter(s) denote significantly different results using Fisher's LSD test, $a=0.05$

course of the entire experimentation (Fig. 1). Similarly, enhanced mortality response of 2049 over time was reported against Coptotermes formosanus Shiraki (Hussain et al. 2017) and Ocinara varians Walker (Hussain et al. 2009). These findings showed that the effectiveness of 2049 in terms of pathogenicity against all these hosts revealed a valuable feature of being a broad-spectrum mycopathogen.

The acaricidal potential of $M$. anisopliae isolates against $O$. afrasiaticus, evaluated here, exhibited a concentration-dependent mortality response (Fig. 2). However, significant differences in mortality at all tested concentrations $(F=148.50 ; \mathrm{df}=4,40 ; P<$ $0.0001)$, with different isolates $(F=639.13 ; \mathrm{df}=2,40$; $P<0.0001)$, and their interactions $(F=14.19 ; d f=8$, 40; $P<0.0001)$ were observed. Maximum mortality (>90\%) was achieved from the treatment in which date-palm leaf disks were treated by the highest concentration $\left(1 \times 10^{9}\right.$ conidia $\left./ \mathrm{ml}\right)$ of 2049 . Overall, 2049 exhibited the lowest $\mathrm{LC}_{50}$ value (Table 1 ). The superiority of 2049 in terms of pathogenicity could be attributed to strong host specificity. On the other hand, isolate 7234 exhibited very high $\mathrm{LT}_{50}$ values (18.44

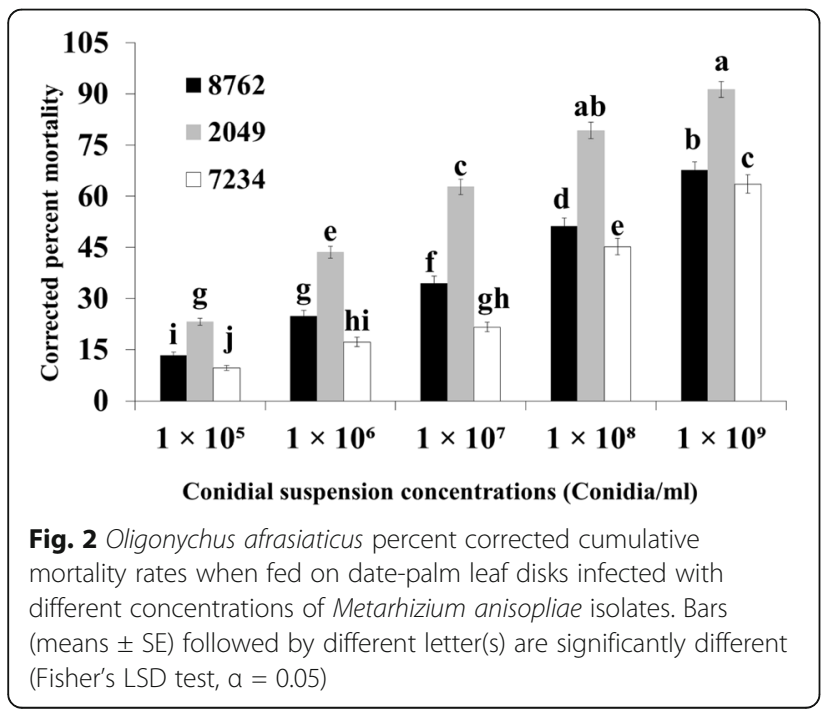

days) due to the slow mortality response. Obtained findings with regard to the low mortality of 7234 are in agreement with Shah et al. (2007), and Hussain et al. (2015), who reported that the low virulence of the fungal isolate was attributed to a little expression of cuticle-degrading proteases (Pr1). Based on these results, it could be suggested that the low mortality rate might due to little abundance of the right set of traits involved in the virulence of EPF.

\section{Evaluation of Oligonychus afrasiaticus antioxidant defense mechanism}

The host has evolved an efficient antioxidant defense system to eliminate reactive oxygen species (ROS) generated as a result of fungal infections. Conidial infection with $M$. anisopliae isolates in the date-palm dust mite induced the enzymatic activities of first-line antioxidant enzymes such as superoxide dismutase (SOD), to catalyze superoxide radicals $\left(\mathrm{O}_{2}{ }^{\bullet-}\right)$ into hydrogen peroxide. Results showed significant differences in the SOD activities of date-palm dust mites calculated at different times $(F=48.55 ; \mathrm{df}=12,24 ; P<0.0001)$, with different fungal isolates $(F=85.27 ; \mathrm{df}=2,24 ; P<0.0001)$, and their interaction $(F=356.29 ; \mathrm{df}=4,24 ; P<$ 0.0001 ) as shown in Table 2. The highest SOD activity, as depicted in the present results, among datepalm dust mites at the start of infection agrees with the results of Gretscher et al. (2016) and Hussain et al. (2017). However, a decline in SOD activities with time from the most virulent isolate 2049, corroborates with AlJabr et al. (2018), who suggested that decline in SOD activities at a lateral infection stage from virulent isolates led to ROS elimination failure. Such circumstances may stop the cellular processes of the target host by the denaturation of biomolecules (AlJabr et al. 2018).

Catalase is an important antioxidant defense enzyme that protects key cellular elements against oxidative damages by metabolizing $\mathrm{H}_{2} \mathrm{O}_{2}$ into hydrogen and oxygen. Infections of $M$. anisopliae isolates induced different levels of CAT activities (Table 2). Date-palm dust mite exposure to different isolates of $M$. 
Table 2 Relative antioxidant enzymes activities of date-palm dust mite upon exposure to different isolates of $M$. anisopliae under laboratory conditions

\begin{tabular}{|c|c|c|c|c|c|}
\hline \multirow[t]{2}{*}{ Enzymes } & \multirow[t]{2}{*}{ Isolate } & \multicolumn{3}{|c|}{ Post-exposure duration } & \multirow{2}{*}{$\begin{array}{l}\text { Time response } \\
\text { statistics }\end{array}$} \\
\hline & & 4 days & 8 days & 12 days & \\
\hline \multirow[t]{3}{*}{ Relative SOD activities } & 2049 & $45.45 \pm 1.63^{c}$ & $73.41 \pm 2.05^{\mathrm{a}}$ & $13.15 \pm 1.42^{9}$ & \multirow{3}{*}{$\begin{array}{l}F=48.55 \\
d f=12,24 \\
P<0.0001\end{array}$} \\
\hline & 8762 & $19.13 \pm 1.25^{f}$ & $33.82 \pm 1.68^{\mathrm{d}}$ & $45.11 \pm 1.85^{c}$ & \\
\hline & 7234 & $27.11 \pm 1.64^{\mathrm{e}}$ & $45.16 \pm 1.89^{c}$ & $57.22 \pm 2.17^{b}$ & \\
\hline \multicolumn{2}{|c|}{ Isolate response statistics } & \multicolumn{3}{|c|}{$F=85.27 ; \mathrm{df}=2,24 ; P<0.0001$} & \\
\hline \multirow[t]{3}{*}{ Relative CAT activities } & 2049 & $41.62 \pm 1.94^{c}$ & $62.65 \pm 2.27^{\mathrm{a}}$ & $14.89 \pm 1.22^{f}$ & \multirow{3}{*}{$\begin{array}{l}F=49.39 \\
d f=12,24 \\
P<0.0001\end{array}$} \\
\hline & 8762 & $21.58 \pm 0.98^{e}$ & $31.18 \pm 1.20^{d}$ & $47.35 \pm 2.29^{b}$ & \\
\hline & 7234 & $23.36 \pm 0.95^{e}$ & $38.31 \pm 1.46^{c}$ & $51.04 \pm 2.02^{b}$ & \\
\hline \multicolumn{2}{|c|}{ Isolate response statistics } & \multicolumn{3}{|c|}{$F=12.91 ; \mathrm{df}=2,24 ; P<0.0001$} & \\
\hline \multirow[t]{3}{*}{ Relative GST activities } & 2049 & $31.85 \pm 2.24^{d}$ & $81.52 \pm 2.45^{\mathrm{a}}$ & $11.09 \pm 0.88^{f}$ & \multirow{3}{*}{$\begin{array}{l}F=200.49 \\
d f=12,24 \\
P<0.0001\end{array}$} \\
\hline & 8762 & $17.94 \pm 1.45^{\mathrm{e}}$ & $36.85 \pm 1.72^{c d}$ & $57.19 \pm 1.84^{\mathrm{b}}$ & \\
\hline & 7234 & $21.32 \pm 0.80^{\mathrm{e}}$ & $40.81 \pm 2.41^{c}$ & $59.92 \pm 2.70^{b}$ & \\
\hline Isolate response stati & \multicolumn{4}{|c|}{$F=3.64 ; \mathrm{df}=2,24 ; P<0.05$} & \\
\hline
\end{tabular}

Means \pm SE values with different letter(s) denote significantly different results using Fisher's LSD test, $a=0.05$

anisopliae $(F=12.91 ; \mathrm{df}=2,24 ; P<0.0001)$, different intervals $(F=49.39 ; \mathrm{df}=12,24 ; P<0.0001)$, and their interactions $(F=156.55$; df $=4,24 ; P<0.0001)$ revealed significant differences in CAT activities. The most virulent 2049 isolate, established in the present study revealed low CAT activities. These findings suggest that reduced CAT activities slows down the elimination of reactive oxygen species. Reduced CAT expression, corroborated here and reported before by Jia et al. (2016), is in agreement with the previous study on toxin-pathogen synergy evaluation by the exploration of host-pathogen interactions (AlJabr et al., 2018). On the other hand, high CAT activities at the lateral stages of the experiment from the date-palm dust mite infected with the least virulent isolate 7234 suggest the safe removal of ROS.

Infectivity of all tested isolates of $M$. anisopliae $(F=3.64$; $\mathrm{df}=2,24 ; P<0.05)$, at different time intervals $(F=200.49$; $\mathrm{df}=12,24 ; P<0.0001)$, and their interactions $(F=175.09$; $\mathrm{df}=4,24 ; P<0.0001)$, revealed significant differences in glutathione S-transferases (GSTs) activities of the date-palm dust mite (Table 2). The patterns of GST activities depicted in the present study are in agreement with previous studies that described low relative GST activities from the most potent treatment (Jia et al. 2016 and AlJabr et al. 2018). Such a pattern may suggest that infectivity of conidial suspensions regulates GST activities and variations among different treatments are mainly because of the virulence of the isolates.

\section{Conclusion}

The present study on the host-pathogen interaction for the first time reported the virulence of $M$. anisopliae isolates as bio-agents against the date-palm dust mite, O. afrasiaticus. Virulence-determinant traits of M. anisopliae 2049 successfully evade the antioxidant defense mechanism of the mite, resulting in its death. Future studies should focus on the formulation and application of strategies to develop eco-friendly mycopathogen-based biological control management of the date-palm dust mite.

\section{Abbreviations}

ANOVA: Analysis of variance; CAT: Catalase; CDNB: Chloro-dinitro-benzene; Cl: Confidence interval; DCNB: Dichloro-nitrobenzene; EBCL: European Biological Control Laboratory; FAO: Food and Agriculture Organization; GST: Glutathione S-transferase; KSA: Kingdom of Saudi Arabia; LC 50 : Lethal concentration to impart 50\% mortality; LSD: Least significant difference; $\mathrm{LT}_{50}$ : Lethal time to impart 50\% mortality; NA: Nitroanilide; PDA: Potato dextrose agar; Pr1: Protease1; RH: Relative humidity; ROS: Reactive oxygen species; SOD: Superoxide dismutase; USDA-ARS: United States Department of Agriculture-Agricultural Research Service

\section{Acknowledgements}

We would like to thank USDA-ARS for providing fungal isolates of entomopathogenic fungi.

\section{Authors' contributions}

The authors carried out all the experiments including the bioassays, analytical part, data analysis, wrote the manuscript, reviewed, and edited the manuscript. All authors read and approved the final manuscript.

\section{Funding}

This research was funded by King Abdul Aziz City for Science and Technology, Kingdom of Saudi Arabia, grant number AT-34-293.

\section{Availability of data and materials}

All data of the study have been presented in the manuscript, and high quality and grade materials were used in this study.

Ethics approval and consent to participate Not applicable. 


\section{Consent for publication}

This study does not contain any individual person's data. All the authors agree to submit this manuscript.

\section{Competing interests}

The authors declare that they have no competing interests.

\begin{abstract}
Author details
'Laboratory of Bio-Control and Molecular Biology, Department of Arid Land Agriculture, College of Agricultural and Food Sciences, King Faisal University, Hofuf, 31982 Al-Ahsa, Kingdom of Saudi Arabia. ${ }^{2}$ National Agriculture Technology Center, Life science and Environment Research Institute, King Abdulaziz City for Science and Technology, P.O. Box 6086, Riyadh 11442, Kingdom of Saudi Arabia. ${ }^{3}$ Ministry of Environment, Water and Agriculture, Riyadh 11442, Kingdom of Saudi Arabia. ${ }^{4}$ RPW Consultant, United Nations, Food and Agriculture Organization (FAO), Riyadh 11442, Kingdom of Saudi Arabia.
\end{abstract}

Received: 17 April 2019 Accepted: 29 August 2019

Published online: 07 September 2019

\section{References}

Abbott WS (1925) A method of computing the effectiveness of an insecticide. J Econ Entomol 18:265-267. https://doi.org/10.1093/jee/18.2.265a

Aebi H (1984) Catalase in vitro. Methods Enzymol 105:121-126. https://doi.org/10. 1016/s0076-6879(84)05016-3

Ali S, Faroogi MA, Sajjad A (2018) Compatibility of entomopathogenic fungi and botanical extracts against the wheat aphid, Sitobion avenae (Fab.) (Hemiptera: Aphididae). Egypt J Biol Pest Control 28:97. https://doi.org/10.1186/s41938018-0101-9

AlJabr A, Hussain A, Rizwan-ul-haq M (2018) Toxin-Pathogen synergy reshaping detoxification and antioxidant defense mechanism of Oligonychus afrasiaticus (McGregor). Molecules 23:1978. https://doi.org/10.3390/molecules23081978

Amalin DM, Peña JE, Yu SJ (2000) Selective toxicity of some pesticides to Hibana velox (Araneae: Anyphaenidae), a predator of Citrus leafminer. Florida Entomol 83:254-261. https://doi.org/10.2307/3496343

Beauchamp C, Fridovich I (1971) Superoxide dismutase: Improved assays and an assay applicable to acrylamide gels. Anal Biochem 44:276-287. https://doi. org/10.1016/0003-2697(71)90370-8

Bradford MM (1976) A rapid and sensitive method for the quantitation of microgram quantities of protein utilizing the principle of protein-dye binding. Anal Biochem 72:248-254. https://doi.org/10.1016/00032697(76)90527-3

Diallo H (2005) The role of date palm in combat desertification. In: The date palm: From traditional resource to green wealth, Abu Dhabi, pp 13-19

EL-Saeid MH, AL-Dosari SA (2010) Monitoring of pesticide residues in Riyadh dates by SFE, MSE, SFC, and GC techniques. Arab J Chem 3:179-186. https:// doi.org/10.1016/j.arabjc.2010.04.007

Gretscher RR, Streicher PE, Strauß AS, Wielsch N, Stock M, Wang D, Boland W, Burse A (2016) A common theme in extracellular fluids of beetles: extracellular superoxide dismutases crucial for balancing ROS in response to microbial challenge. Sci Rep 6:24082. https://doi.org/10.1038/srep24082

Habig WH, Pabst MJ, Jakoby WB (1974) Glutathione S-transferases. The first enzymatic step in mercapturic acid formation. J Biol Chem 249:7130-7139

Hussain A (2018) Reprogramming the virulence: Insect defense molecules navigating the epigenetic landscape of Metarhizium robertsii. Virulence 9: 447-449. https://doi.org/10.1080/21505594.2017.1421828

Hussain A, Rizwan-ul-Haq M, Al-Ayedh H, Ahmed S, AlJabr AM (2015) Effect of Beauveria bassiana infection on the feeding performance and antioxidant defence of red palm weevil, Rhynchophorus ferrugineus. BioControl 60:849859. https://doi.org/10.1007/s10526-015-9682-3

Hussain A, Rizwan-ul-Haq M, Al-Ayedh H, AlJabr A (2016) Susceptibility and immune defence mechanisms of Rhynchophorus ferrugineus (Olivier) (Coleoptera: Curculionidae) against entomopathogenic fungal infections. Int J Mol Sci 17:1518. https://doi.org/10.3390/ijms17091518

Hussain A, Tian MY, He YR (2010) In vitro and in vivo culturing impacts on the virulence characteristics of serially passed entomopathogenic fungi. J Food, Agric Environ 8:481-487

Hussain A, Tian MY, He YR, Ahmed S (2009) Entomopathogenic fungi disturbed the larval growth and feeding performance of Ocinara varians (Lepidoptera:
Bombycidae) larvae. Insect Sci 16:511-517. https://doi.org/10.1111/j.17447917.2009.01272.x

Hussain A, Tian MY, Wen SY (2017) Exploring the caste-specific multi-layer defense mechanism of formosan subterranean termites, Coptotermes formosanus Shiraki. Int J Mol Sci 18:2694. https://doi.org/10.3390/ ijms18122694

Hussain A, Tian MY, Wen SY (2018) Proteomic analysis of Formosan Subterranean Termites during exposure to entomopathogenic fungi. Curr Proteomics 15: 229-240. https://doi.org/10.2174/1570164615666180315110714

Jia M, Cao G, Li Y (2016) Biochemical basis of synergism between pathogenic fungus Metarhizium anisopliae and insecticide chlorantraniliprole in Locusta migratoria (Meyen). Sci Rep 6:28424. https://doi.org/10.1038/srep28424

Shah FA, Allen N, Wright CJ, Butt TM (2007) Repeated in vitro subculturing alters spore surface properties and virulence of Metarhizium anisopliae. FEMS Microbiol Lett 276:60-66. https://doi.org/10.1111/j.1574-6968.2007.00927.x

St. Leger RJ, Cooper RM, Charnley AK (1987a) Production of cuticle-degrading enzymes by the entomopathogen Metarhizium anisopliae during infection of cuticles from Calliphora vomitoria and Manduca sexta. Microbiology 133: 1371-1382. https://doi.org/10.1099/00221287-133-5-1371

St. Leger RJ, Cooper RM, Charnley AK (1987b) Distribution of chymoelastases and trypsin-like enzymes in five species of entomopathogenic deuteromycetes. Arch Biochem Biophys 258:123-131. https://doi.org/10.1016/00039861(87)90329-8

St. Leger RJ, Durrands PK, Charnley AK, Cooper RM (1988) Role of extracellular chymoelastase in the virulence of Metarhizium anisopliae for Manduca sexta. J Invertebr Pathol 52:285-293. https://doi.org/10.1016/0022-2011(88)90137-1 Statistix (2003) Statistix 8.1. Analytical Software, Tallahassee

\section{Publisher's Note}

Springer Nature remains neutral with regard to jurisdictional claims in published maps and institutional affiliations.

\section{Submit your manuscript to a SpringerOpen ${ }^{\circ}$ journal and benefit from:}

- Convenient online submission

- Rigorous peer review

- Open access: articles freely available online

High visibility within the field

- Retaining the copyright to your article

Submit your next manuscript at $\boldsymbol{\nabla}$ springeropen.com 